\title{
ARTIGOS
}

Submetido 28.05.2014. Aprovado 05.09.2014

Avaliado pelo processo de double blind review. Editor Científico: Sergio Bulgacov

DOI: http://dx.doi.org/10.1590/So034-759020150605

\section{PRATICANTES DA ESTRATÉGIA E AS BASES PRAXEOLÓGICAS DA INDÚSTRIA DO MANAGEMENT}

\author{
Strategy practitioners and the praxeological foundations of management \\ industry
}

\author{
Practicantes de la estrategia y las bases praxeológicas de la industria del \\ management
}

\section{RESUMO}

No presente artigo, tentou-se ir além das explicações tradicionais sobre as modas gerenciais que configuram a indústria do management. Para tanto, foi adotada uma perspectiva praxeológica ao examinar as bases de sustentação dessa indústria. Os dados foram coletados durante um período de sete meses via observação, pesquisa documental e entrevistas em uma organização do emergente setor dos sites de vendas de cupons de desconto. A análise do processo de construção social dos praticantes da estratégia em diferentes domínios hierárquicos revelou que a dinâmica ordinária no interior das organizações que dá sustentação à indústria do management ocorre por meio da articulação entre práxis centrais e periféricas da estratégia, discurso, trajetória social, e uma estratificação de três categorias de papéis organizacionais.

PALAVRAS-CHAVE | Práxis, praticantes, indústria do management, hierarquia, discurso.

\begin{abstract}
This paper goes beyond traditional explanations about the managerial fads that shape the management industry. Therefore, a praxeological perspective was adopted to examine the bases underlying this industry. Data were collected during a seven-month period through observation, documental research and interviews that were conducted within an organization in the emerging sector of online discount coupon selling. We analyzed the social construction process of strategy practitioners in different hierarchical domains and found that the ordinary dynamics within organizations - which are at the base of the management industry - occur through the articulation of central and peripheral strategy, discourse, and social trajectory praxes, and through the stratification of three organizational role categories.
\end{abstract}

KEYWORDS | Praxis, practitioners, management industry, hierarchy, discourse.

\section{CRISTIANO OLIVEIRA MACIEL}

cristiano.maciel@pucpr.br Professor da Pontifícia Universidade Católica, Escola de Negócios Curitiba - PR, Brasil

\section{PAULO OTÁVIO MUSSI AUGUSTO}

paulo.mussi@pucpr.br

Professor da Pontifícia Universidade Católica, Escola de Negócios -

Curitiba - PR, Brasil

\section{RESUMEN}

En el presente artículo, se intentó ir más allá de las explicaciones tradicionales sobre las modas administrativas que configuran la industria del management. Para eso, fue adoptada una perspectiva praxiológica al examinar las bases de sustentación de esa industria. Los datos fueron recolectados durante un período de siete meses por medio de observación, investigación documental y entrevistas en una organización del emergente sector de los sitios de ventas de cupones de descuento. El análisis del proceso de construcción social de los practicantes de la estrategia en diferentes dominios jerárquicos reveló que la dinámica ordinaria en el interior de las organizaciones que da sustentación a la industria del management ocurre por medio de la articulación entre praxis centrales y periféricas de la estrategia, discurso, trayectoria social, y una estratificación de tres categorías de papeles organizacionales.

PALABRAS CLAVE I Praxis, practicantes, industria del management, jerarquía, discurso. 


\section{INTRODUÇÃO}

A gestão organizacional absorve continuamente novas práticas, ideias, conceitos e ferramentas que revelam a influência das modas gerenciais (Gibson \& Tesone, 2001; Giroux, 2006; Perkmann \& Spicer, 2008). Modas gerenciais são práticas apresentadas como técnicas, ferramentas, modelos e lógicas de ação produzidas e difundidas via textos e fala de professores, consultores, gurus, escolas de negócios e mídia especializada, e largamente aplicadas por seus consumidores, constituindo a indústria do management. 0 termo não deve ser confundido com modismo gerencial, que ocorre quando novas técnicas gozam de alguma popularidade, mas por espaço curto de tempo (Abrahamson \& Eisenman, 2008; Perkmann \& Spicer, 2008). De fato, tanto modas quanto modismos são transacionados na indústria do management (Abrahamson \& Eisenman, 2008).

Faz-se necessário observar que as trocas entre produtores e consumidores nessa indústria estão, em grande medida, associadas ao adjetivo "estratégico". Isso ocorre, sobretudo, em função do status da administração estratégica nesse mercado. Já na década de 1970, Mintzberg, Raisinghani, e Théorêt (1976) atentaram para a frequente atribuição do termo estratégico a tudo que seja considerado importante pelas organizações. Na indústria do management, o campo da estratégia (Whittington, 2006) tem desempenhado um papel central no que concerne à legitimação de várias modas gerenciais, formatando termos como: gestão estratégica de pessoas, gestão estratégica da qualidade, equipes estratégicas, indicadores estratégicos, gestão estratégica de custos e aprendizagem estratégica.

Entretanto, abordagens da própria área de estratégia, que tanto contribui para geração e legitimação do conhecimento transacionado nesse mercado, têm raramente sido empregadas visando à compreensão da indústria do management. Essa indústria tem sido analisada via frameworks com orientações sociopsicológicas, tecnoeconômicas (e.g., Abrahamson, 1991, 1996), culturais e institucionais (e.g., Abrahamson \& Eisenman, 2008; Czarniawska \& Panozzo, 2008; Perkmann \& Spicer, 2008).

De tal crítica, decorre o argumento do presente estudo: uma perspectiva voltada à práxis social da estratégia (Reed, 1984; Whittington, 2006), cujos fundamentos estão centrados na virada da prática da teoria social contemporânea (Schatzki, 2001), pode evidenciar as bases praxeológicas da dinâmica que sustenta a indústria do management. Tal perspectiva se diferencia de esforços anteriores ao passo que considera qualquer tipo de ator social (executivos, membros organizacionais da base da hierarquia, consultores, gurus) como um praticante da estratégia. $\mathrm{Na}$ medida em que qualquer desses praticantes coloca em uso, por meio da práxis, essas ferramentas ou conceitos (Whittington,
2006), ele opera na transformação ou sustentação da indústria do management por meio de seus efeitos nas modas gerenciais. De modo geral, a práxis, atividade material no plano micro, relaciona-se recursivamente (Giddens, 1989) com as modas gerenciais (instituições no plano macro) da indústria do management. Compreender as práticas em uso, aquilo que o pesquisador observa in loco no plano micro nas organizações (Whittington, 2006), pode contribuir para esclarecer como se sustenta a indústria do management no plano macro.

A partir dessa perspectiva de open strategy (Whittington, Caillluet, \& Yakis-Douglas, 2011), que abre espaço para inclusão de vários tipos de atores sociais na observação da prática do management, delineou-se o seguinte objetivo de pesquisa: explicar como o processo de construção social dos praticantes da estratégia (constituição simbólica e objetivação de seus papéis por meio da práxis da estratégia) em diferentes domínios hierárquicos de uma organização de um setor emergente, portanto mais sensível à modas gerenciais em função de maior incerteza (Jansson, 2011), se relaciona com a sustentação da indústria do management.

\section{A INDÚSTRIA DO MANAGEMENT E SEUS ELEMENTOS DE SUSTENTAÇÃO}

O conjunto de práticas, ideias, conceitos e ferramentas aplicadas na gestão organizacional tem sido tratado mais criticamente por alguns autores sob o rótulo de indústria do management, e a partir de reflexões sobre modas e modismos gerenciais (Abrahamson, 1996; Abrahamson \& Eisenman, 2008; Abrahamson \& Fairchild, 1999; Benders \& Bijsterveld, 2000; Caldas \& Wood, 2000; Czarniawska \& Panozzo, 2008; Mamman, 2002). Esses e outros pesquisadores têm pontuado o modo como alguns atores sociais desempenham um papel central na proposição e também na disseminação de ideologias (Amernic, Losell, \& Craig, 2000), conceitos (Benders, 1999; Scarbrough \& Swan, 2001) e novas técnicas de gestão.

Vários estudos têm explorado os elementos que dão sustentação a essa indústria. Os trabalhos nessa direção atentam essencialmente para os modos com que o management se transforma e se reinventa continuamente. Carson, Lanier, Carson, e Guidry (2000), por exemplo, examinaram a crescente reinvenção das práticas e ferramentas da indústria do management. Os autores pesquisaram 16 técnicas gerenciais que emergiram entre os anos 1950 e 1990 com o objetivo de avaliar seus ciclos de vida. Os achados do estudo apontaram que a velocidade de propostas de novas técnicas acelerou-se, pois aquelas com maior penetração tiveram seus ciclos cada vez mais curtos, e com isso tornaram-se mais difíceis de implementar. 
No Brasil, por exemplo, Caldas e Wood (2000) debruçaram-se sobre a adoção dos sistemas integrados de gestão (SIGs). Tendo como análise um total de 28 experiências de adoção desse tipo de sistema, os autores destacaram a relação de interdependência entre fatores substantivos, políticos e institucionais na sua difusão. Por meio dessa visão multidimensional, os pesquisadores esclareceram que a difusão dos SIGs foi caracterizada por falta de reflexão sobre a necessidade real do sistema, insucessos por conta de simplificação do que era exigido em relação ao processo de implementação e por insatisfações, mas fortemente baseada em uma lógica cerimonial. Nicolai, Schulz, e Thomas (2010) também apontaram a presença de aspectos simbólicos a partir de um exame da influência de conceitos gerenciais sobre avaliações de analistas de risco de organizações em Wall Street. Os autores do estudo verificaram se os analistas avaliavam mais positivamente organizações que incorporavam o conceito de competência essencial. 0 consumo desse conceito pelos analistas fez com que eles supervalorizassem os ganhos futuros das empresas que empregaram em seus documentos o discurso da competência essencial. Esse resultado corrobora a afirmação de Lang e Ohana (2012) de que modas gerenciais ajudam, mas também podem representar perigos para as organizações.

Considerando tanto aspectos técnicos quanto simbólicos, Abrahamson (1996) apresentou um framework para análise das modas gerenciais enfatizando produtores e consumidores da indústria do management. De acordo com o autor, essa indústria é constituída por vários tipos de atores sociais voltados a transformação e reprodução de um sistema pretensamente orientado a garantir eficiência e eficácia a todo tipo de organização. De acordo com Abrahamson (1996), essa indústria se renova a partir de um sistema retroalimentado de modas gerenciais, o qual é sustentado reciprocamente por esses dois tipos de atores. De um lado, no grupo dos produtores, têm-se, por exemplo, gurus da administração, consultores e professores renomados representando suas escolas de negócios. De outro, no grupo dos consumidores, estão empresários, executivos, alunos e a mídia especializada; seus mais importantes elementos. Vale destacar que, no plano individual, vários atores desempenham múltiplos papéis, tanto de produtores quanto de consumidores. De acordo com Abrahamson (1996), os seguintes imperativos dão sustentação a essa indústria: (i) normas de racionalidade e de progresso, que afetam o mercado do conhecimento gerencial; e (ii) forças sociopsicológicas e tecnoeconômicas, que influenciam os consumidores que demandam tal conhecimento.

Para explicar como normas de racionalidade e progresso sustentam a indústria do management, Abrahamson (1996) apoia-se na perspectiva institucional de análise organizacional. A partir daí, normas de racionalidade são compreendidas como orientações constituídas simbolicamente, e, entre os significa- dos mais importantes associados a essas normas, está a noção de eficiência. Há a expectativa de que atores organizacionais se comportem de modo racional, o que significa necessariamente de modo eficiente. Ações organizacionais que priorizem valores que destoam da eficiência são tidas como irracionais. Normas de progresso estão associadas ao contínuo aperfeiçoamento da gestão, de que nunca são exauridas as possibilidades de mudança. Nesses termos, não esperar por mudanças (caso dos consumidores da indústria do management) e não ocasionar mudanças (caso dos produtores da indústria do management) significaria ser penalizado em termos de legitimidade (Suchman, 1995). Para explicar como essas forças concorrem na influência sobre os consumidores de novas modas gerenciais, Abrahamson (1996) baseia-se em teorias econômicas, políticas, organizacionais e também na psicologia da estética da moda. Nesse sentido, no plano sociopsicológico, a demanda por inovações nas técnicas gerenciais ocorre em função: (i) das frustrações dos consumidores (e.g., executivos) com as atuais ferramentas de gestão; (ii) do tédio e da expectativa da novidade; e (iii) pela necessidade de diferenciação de status possibilitada pelo uso de uma ou outra técnica tida como mais sofisticada. Na esfera tecnoeconômica, a demanda surge da avaliação dos consumidores de que existem diferenças entre o desempenho atual e o desempenho possível das técnicas de gestão.

Em conjunto, normas de racionalidade e de progresso fazem com que melhorias na eficiência das organizações sejam vistas como dependentes diretas das melhorias nas técnicas de gestão, que frequentemente são recebidas por seus consumidores como infalíveis e sem questionamentos. Assim, a busca contínua pelo aumento da eficiência organizacional cria demandas constantes por técnicas administrativas, que consequentemente contribuem para a reinvenção do corpus que constitui aquilo que é transacionado entre produtores e consumidores na indústria do management. Ademais, Abrahamson (1996) destaca a existência de um homem movido pela vaidade do status, pela frustração e pela vontade do novo, bem como influenciado por elementos tidos como racionais que se conformam na noção de desempenho. A lógica técnica e econômica faz com que a comparação entre o alcançado e o não alcançado, em termos de desempenho, crie a demanda por promessas de melhorias. Logo, conclui-se, a partir do framework de Abrahamson (1996), que a indústria do management é sustentada: culturalmente, sociopsicologicamente, tecnicamente e economicamente por modas gerenciais.

Contudo, há de se criticar que Abrahamson (1996) desconsidera que a sustentação dessa indústria ocorra fundamentalmente no plano praxeológico, na esfera em que os atores sociais fazem o exercício do management, onde se dá a aplica- 
ção local e situada no tempo e no espaço de tais modas. Ainda que, em partes, o autor considere, a partir da nova teoria institucional, a dimensão cultural em suas teorizações, o nível de análise permanece longe da práxis e da atividade idiossincrática dos praticantes da gestão. Logo, propõe-se aqui a consideração dos elementos de sustentação da indústria do management a partir da atual virada da prática na teoria social e no campo da estratégia (Whittington, 2006). Tal ontologia (Schatzki, 2001, 2005) é um desdobramento da virada interpretativa e da virada linguística nas ciências sociais. Ela assume a práxis, a atividade situada no tempo e no espaço (Giddens, 1989), como o elemento aglutinador de instituições, artefatos, movimentos, cognição, motivações, emoções, interações, linguagem e poder. Esses elementos somam-se e constituem o que Schatzki (2001) denomina campos de práticas.

É nessa direção que uma visão praxeológica da estratégia (Schatzki, 2001, 2005, 2006) pode esclarecer, conforme proposto aqui, o modo como o processo de construção social dos praticantes da estratégia se relaciona com a sustentação da indústria do management. Tal abordagem é adequada na medida em que considera a práxis como o lócus no qual elementos que são apresentados hierarquicamente (institucional, organizacional, individual) por outras ontologias convergem situacionalmente (Schatzki, 2001, 2005) no mesmo nível ou site social. Portanto, a práxis é a materialização das sobreposições, influências, conflitos e convergências de todos esses elementos na situação - contexto micro localizado no tempo e no espaço - na qual interagem os diversos atores sociais que contribuem para a construção social das diferentes noções de praticantes e de estratégia, e, por isso, permite analisar, como até então não realizado, as bases praxeológicas de sustentação da indústria do management.

\section{O “lugar” da práxis e dos praticantes na sustentação da indústria do management}

A visão praxeológica acerca da estratégia é um dos principais movimentos teóricos voltados ao exame do papel dos praticantes da ação nas organizações. A preocupação com a construção ou formação dos praticantes da estratégia foi uma característica que distinguiu, por exemplo, a abordagem da strategy as practice em sua concepção, quando proposta por Whittington (1996). A atenção direcionada ao praticante da estratégia estendeu-se para além de sua eficácia e dos seus processos de formação, e destacou também a importância da investigação sobre a construção social desses atores sociais e necessariamente a sua relação com as instituições. Em um texto que marcou 10 anos da proposta inicial, o próprio Whittington (2006) chamou atenção, entre outras coisas, para a relação entre praticantes, suas práxis e as instituições do campo da estratégia (i.e., práticas). Por meio dessa aliteração de três Ps, o autor enfatizou que aquilo que os praticantes da estratégia fazem tem implicações para o campo da estratégia em nível institucional, pois regras institucionais, como emprego da análise SWOT ou da cadeia de valor, têm sua vigência social estabelecida no que frequentemente se designa por plano micro. Se praticantes desempenham práxis que empregam essas práticas, tais práticas continuam vivas, porque estão sendo reproduzidas - se elas não ocorrem como atividade localizada, elas deixam de existir como traços de memória (Giddens, 1989).

Essas assertivas justificam o argumento de que a indústria do management tem sua continuidade atrelada ao processo de construção social dos praticantes da estratégia. Em função dos significados atribuídos a ser um praticante mais central e menos periférico da estratégia, os significados associados ao cargo de diretor de uma organização, por exemplo, é que um grande número de atores sociais tem suas expectativas ampliadas e renovadas em relação ao que a indústria do management pode lhes oferecer. Se um grande contingente de atores sociais, membros das organizações, espera por novos conceitos e técnicas gerenciais e eles constroem socialmente seus papéis de praticantes, por meio do uso e da interação com tais elementos, então eles contribuem para a sustentação da indústria do management. Se praticantes da estratégia, mesmo atores organizacionais periféricos, como operários e supervisores, legitimam o uso de conceitos e técnicas dos envolvidos mais centralmente com a estratégia formal, então mesmo praticantes periféricos da estratégia contribuem para a sustentação da indústria do management. Em decorrência dessa reciprocidade que marca teoricamente a relação entre praticantes da estratégia e sustentação da indústria do management, foi proposto o presente trabalho.

\section{PROCEDIMENTOS METODOLÓGICOS}

Os procedimentos metodológicos do estudo foram definidos em termos de contexto da investigação, seleção dos participantes, método e análise de dados. Definiu-se como contexto da pesquisa uma organização sediada em Curitiba (PR) que atua no setor dos guias locais de compra pela internet. 0 modelo de negócio da empresa difere um pouco de empresas como Groupon e Peixe Urbano, pois, em vez de apresentar poucas ofertas diárias, ela oferece centenas de ofertas perenes. Essas ofertas dos estabelecimentos parceiros permanecem durante períodos mais longos no site desse guia local de compras. Além das ofertas, o site também apresenta as opiniões dos consumidores dos serviços dos anunciantes. A empresa posiciona-se como um guia de opiniões e 
ofertas. O seu setor de atuação é considerado emergente e constituído tipicamente por startups gerenciadas por pessoas jovens. Essas características mostram-se interessantes para investigação do processo de construção social dos praticantes da estratégia na medida em que eles se encontram em seus estágios iniciais de formação profissional e, teoricamente, estão mais sensíveis às regras institucionais da estratégia e modas gerenciais em razão das incertezas de um setor emergente (Jansson, 2011). Os dois fundadores da empresa, por exemplo, têm menos de 25 anos.

A definição dessa organização como setting (Maxwell, 2005) de pesquisa serviu como demarcação para seleção dos informantes para investigação de como os praticantes da estratégia são socialmente construídos. Todos os membros organizacionais fizeram parte da observação (Glesne, 1998). No decorrer do estudo, a organização contava com 21 funcionários em média, todos com idade abaixo de 25 anos. Sua estrutura era composta pelos seguintes setores: relacionamento, comercial, tecnologia de informação e administrativo. Essa configuração estrutural, ainda que pouco complexa, possibilitou observar praticantes da estratégia com formações em diferentes áreas e desempenhando distintas atividades.

Em termos de métodos, foram combinadas: observação, pesquisa documental e entrevistas. A pesquisa durou sete meses e contou com coleta de informações do site e arquivos da empresa (Neuman, 1997), observação (Glesne, 1998) de todos os funcionários e sócios, e realização de um total de 13 entrevistas semiestruturadas (Seidman, 1998). A observação foi escolhida como mecanismo principal de coleta de dados em função do problema de pesquisa, o qual exige a observação de práticas, ações e interações entre os atores sociais praticantes da estratégia. Para as anotações das observações, foi criado um arquivo em Word no qual o pesquisador digitava simultaneamente em seu notebook o que acontecia no ambiente da empresa. Essas anotações versaram sobre eventos rotineiros e não rotineiros, sobre as ações dos atores sociais nesses eventos e sobre as características físicas e tecnológicas, conforme recomendado por Glesne (1998). Em poucos casos, não foi possível fazer as anotações enquanto ocorria a observação. Nessas situações, as anotações foram realizadas imediatamente após a saída do pesquisador da organização. Nos finais de semana, as anotações eram verificadas para corrigir possíveis erros e omissões. 0 estado de humor do pesquisador em cada dia de trabalho de campo também foi objeto das anotações para que fosse possível verificar posteriormente suas alterações durante o estudo, conforme as orientações de Glesne (1998).

Para análise dos dados, foram empregadas as técnicas de codificação aberta, axial e seletiva (Strauss \& Corbin, 2008). Esses procedimentos podem ser usados tanto para desenvolvimento de uma grounded theory, geração de teoria substantiva, quanto para um exame mais ordenado dos dados e desenvolvimento de novos conceitos, com destaque para suas propriedades e dimensões. A vantagem do método para o presente estudo é que ele representa uma abordagem qualitativa de inclinação mais construtivista comparado à análise de conteúdo (Mills, Bonner, \& Francis, 2006).

\section{ANÁLISE DOS DADOS E DISCUSSÃO DOS RESULTADOS}

A análise dos dados permitiu um tratamento mais "indutivo" (Strauss \& Corbin, 2008) e a identificação de sete categorias que estão relacionadas à sustentação da indústria do management. Essas categorias são: (i) arenas sociais; (ii) trajetória social dos praticantes da estratégia; (iii) práxis centrais da estratégia; (iv) práxis periféricas da estratégia; (v) dotação social (como verbo, processo de aplicação de habilidades) dos praticantes da estratégia; (vi) discurso da dotação social (como substantivo) estratégica; e (vii) constituição simbólica do praticante da estratégia. Na sequência, foram especificadas as conceituações e relações teóricas entre elas.

O conceito de (i) arenas sociais, inspirado na noção de grupos de referência (Shibutani, 1955), representa a ideia de um espaço ocupado por múltiplos atores sociais com as suas específicas rotinas de funcionamento. Em relação aos atores sociais que fizeram parte do estudo, constataram-se participações em cinco principais arenas com influência nos praticantes: (a) organização de trabalho; (b) família; (c) amigos; (d) organizações de experiência profissional, tais como: empresa júnior, associações internacionais de estudantes, organizações com programas de trainee; e (e) instituições de ensino. Cada um desses espaços caracteriza-se como lócus de debate de diversas questões, gerando conflitos em função de posições contrárias, lutas, negociação, mas também síntese. Arenas sociais são definidas por seus próprios atores por meio das realizações de suas experiências de vida. Elas ajudam a demarcar os limites dos principais contextos de interação que condicionaram e condicionam a produção de significados e a formação das habilidades sociais dos praticantes da estratégia. A categoria (ii) trajetória social dos praticantes da estratégia revela o trânsito do ator organizacional entre as arenas que marcaram sua constituição. Essa categoria permite identificar quais arenas sociais fizeram parte da história dos atores e contribuíram no processo de obtenção, acumulação, renovação e, sobretudo aplicação de suas habilidades sociais, bem como aponta os discursos sociais presentes nessas arenas. Isso significa que tal conceito permite separar os diferentes contextos interacionais, bem como suas influências, ao longo tempo 
biográfico dos atores sociais. No presente estudo, constatou-se que a trajetória dos pesquisados, ou seja, praticantes da estratégia de diferentes domínios hierárquicos, variou principalmente em função da afiliação temporária ou mais permanente em algumas das arenas sociais e também em razão do discurso presente nessas arenas. Os excertos de uma das entrevistas exemplificam a variação de arenas no decorrer da trajetória social e sua influência sobre o praticante.

Fui diretor de marketing, lá da JR (i.e., Empresa Júnior) [...] Depois saí de lá e fui para a empresa de fusões de aquisições que te falei, que trabalhava com o (i.e., amigo que se tornou sócio da empresa posteriormente). Aí comecei agilizar minha saída e saí. Me formei na minha faculdade (i.e., Administração na UFPR). Aí já comecei a estudar, uns seis meses só estudando e montando o plano de negócios do (i.e., empresa pesquisada). [...] Meu pai é formado em Direito e hoje ele tem um escritório. Mas ele já teve muita empresa. Ele teve umas cinco ou seis empresas. Ele mesmo fala assim: se eu tivesse conhecimento de gestão, de financeira e tal. Ele já teve hotel, já teve indústria pesqueira e tal (Entrevistado 2, Administrador, sócio diretor, 24 anos).

As categorias práxis centrais e práxis periféricas da estratégia são separadas apenas analiticamente aqui, pois a estratégia é definida como a organização em sua totalidade. Whittington e Melin (2003, p. 37) afirmam que "estratégia e organização formam uma dualidade integrada”, colocam organizing e strategizing em paralelo e ilustram essa lógica pela seguinte fala de um executivo: “Nossa estratégia é nossa organização". Tal definição de estratégia está em linha com uma abordagem prática de open strategy (Whittington et al., 2011). Essa abordagem implica admitir que existam um ou poucos indivíduos que atuam como estrategistas formais de fato, mas destaca que todos os atores organizacionais atuam como praticantes da estratégia. Nesse sentido, dicotomias como quem planeja e quem executa a estratégia, ou entre formulação e implementação, perdem importância (Whittington, 1996). Mesmo em abordagens tradicionalmente funcionalistas, podem ser encontrados pressupostos da concepção de organização como estratégia. Barney (1996) define estratégia como alocação de recursos. Se todo e qualquer ativo tangível ou intangível presente na organização é um tipo de recurso, então a organização como um todo passa a ser sua estratégia. Apenas em termos de operacionalização, são realizadas demarcações a partir de competências ou rotinas, por exemplo. Mintzberg, Ahlstrand, e Lampel (2010, p. 122) discordam das definições muito estreitas de estratégia, como a da escola de posicionamento, e afirmam em contraposição Porter (1996): “Mas o que há de errado em ver estratégia em 'tudo que uma empresa faz ou consiste’? Isto é simplesmente estratégia como perspectiva". Portanto, classi- ficar qualquer atividade organizacional como práxis central ou como práxis periférica permite que seja alargada a amplitude de análise de algumas das lentes teóricas que figuram no campo da estratégia e que adotam pressupostos ontológicos e epistemológicos não funcionalistas.

O conceito de (iii) práxis centrais da estratégia agrega atividades corporais, expressões emocionais, comunicação, uso de objetos e decisões. 0 material textual de documentos, notas de campo, entrevistas e também fotos possibilitou verificar a recorrência de várias atividades que puderam ser percebidas como episódios de atividades sequenciais. Essas atividades foram inicialmente separadas entre aquelas mais rotineiras e próximas do núcleo operacional da empresa e aquelas que faziam parte do cotidiano da alta gerência. As atividades que tipicamente envolveram a alta gerência foram agregadas em 23 subcategorias, como: momentos de reflexão sobre alternativas de ação, comparações com os concorrentes, geração de ideias, planejamento formal.

Agora comecei a perceber uma certa regularidade no comportamento do pessoal daqui, pelas anotações. 0 (i.e., sócio diretor) chega depois que o restante do pessoal já chegou e normalmente faz as mesmas coisas: é chegar e fazer um "social" com o pessoal nos dois andares da empresa, ir para o notebook e começar a fazer questionamentos para auxiliar no controle do que está acontecendo na empresa, faz reuniões informais quase todo dia com o pessoal de desenvolvimento do site e geram novas ideias de melhorias e correções nos serviços, comenta sobre o que os concorrentes estão fazendo e uma vez por semana faz reuniões com o pessoal todo e mostra resultados, pede para os demais, principalmente vendedores, contarem o que está dando certo, passa diretrizes citando passagens de consultores e professores que são autores na área de management. Às vezes também apresenta um PowerPoint com as figuras das capas do livro Estratégia Competitiva e do livro A Estratégia do Oceano Azul para explicar aos demais membros da organização a estratégia da empresa (Excerto da observação).

Por sua vez, a noção de (iv) práxis periféricas da estratégia também é constituída por uma série de atividades com maior ou menor interdependência entre si e que foram agregadas em 10 grupos ou subcategorias que envolviam tipicamente os praticantes da estratégia com postos nos níveis hierarquicamente inferiores aos da gestão. Essas práxis periféricas foram designadas: (a) tecnológica (atividades dentro e próximas ao núcleo operacional); (b) artefactual (utilização de materiais e artefatos); (c) confirmatória (verificação de indicadores operacionais); (d) adaptativa (discussões sobre mudanças); (e) interacional (comunicação); (f) vernacular (emprego de termos típicos da organização); (g) simbólica (interação com aspectos simbólicos da 
organização); (h) estrutural (reconstrução de papéis e posições por meio do respeito a regras); (i) posicional (disseminação do conteúdo estratégico); e, (j) sensoiconográfica (sentido individual e compartilhado de que a organização propicia ou não uma base para realização dos projetos pessoais e profissionais dos seus membros). A ideia de práxis periférica está próxima, em termos morfológicos, do conceito de rotinas organizacionais. Entretanto, diferencia-se em termos de ontologia (Schatzki, 2001, 2005) e epistemologia quando são consideradas em campos de práticas. As práxis periféricas tecnológica, interacional e simbólica são representadas respectivamente pelos três excertos da observação.

O vendedor está ligando agora pra falar com um dos clientes e diz que quer fazer uma pesquisa sobre satisfação. Ele fala para o cliente que ele teve mais de 5.000 page views. Ele disse que foram vendidos 7 cupons e quer saber se quer colocar outro cupom ou manter o mesmo (práxis tecnológica). [...] Agora os vendedores estão tentado descobrir, perguntando um para o outro sobre o tipo de produto que uma empresa cliente está oferecendo. Eles perguntam: mas a cerveja é de litro ou 600 ml? (práxis interacional). [...] o cara está de costas para sua baia de trabalho, apenas de meias e com o notebook no colo, parece um ambiente bem descontraído como daquelas empresas de tecnologia que aparecem nas reportagens do Vale do Silício. Outra coisa que reparei é que o trabalho acontece aqui num lugar cheio de coisas diferentes de um escritório que eu consideraria "convencional". $\mathrm{Na}$ parede da escada tem um quadro de 1 metro por $50 \mathrm{~cm}$, mais ou menos, sobre cerveja. 0 pessoal tem coisas de uso pessoal, como xícaras e outros materiais em suas baias e ficam bem descontraídos a ponto de andar pela empresa conversando enquanto escovam os dentes depois de chegar do almoço. Lembro que outro dia estava no piso de baixo e escutei alguém tocar um sino e todos baterem palmas. Tem um sino com um urso de pelúcia em cima dele e quando alguém bate a meta de vendas toca esse sino pra avisar e comemorar (práxis simbólica). (Excerto da observação).

A (v) dotação social (endowing) dos praticantes da estratégia foi conceituada como um conjunto mais parcimonioso de habilidades sociais em ação, que puderam ser extraídas com a observação das práxis centrais da estratégia. Apesar de existirem muitas práxis centrais da estratégia, constatou-se que as habilidades sociais de base (conhecimentos sobre modos de fazer e pensar) dos praticantes eram, muitas vezes, aplicadas em combinações diferentes, mas a partir dos mesmos elementos principais. $\mathrm{Na}$ discussão de produto e na comunicação da estratégia, por exemplo, os praticantes faziam uso do vocabulário da gestão da mesma maneira. Isso revelou que, entre uma grande diversidade de práxis centrais, existem algumas habilidades que são mais comumente aplicadas. As diferentes configurações desse conjunto de habilidades sociais revelam a morfologia de cada práxis. Esses tipos de habilidades ou dotações observadas em ação (endowing) foram designadas:

- Dotação social estratégica cognitiva: pensamento elosequencial (e.g., estabelecimento de relações causais a respeito de organização e ambiente e entre processos organizacionais e desempenho) e conhecimentos técnicos que adquirem status de estratégicos em determinado setor ou organização.

- Dotação social estratégica vernacular: exercício do vocabulário de gestão, termos em inglês, conceitos técnicos, assuntos e padrão de expressões da estratégia que servem como recursos legítimos de linguagem dos gestores organizacionais.

- Dotação social estratégica corporal: padrão de postura corporal, gestos, domínio de distância física e do grau de desenvoltura corporal em momentos de copresença em relação ao comportamento esperado, mais ou menos formal, em situações diversas como reuniões, apresentações da empresa, conversas com outros executivos.

- Dotação social estratégica artefactual: emprego de elementos físicos no trabalho, como roupas consideradas apropriadas, uso de computadores, livros, planilhas e softwares específicos da área de gestão, que são símbolos valorizados no campo da estratégia.

- Dotação social estratégica relacional: mobilização do seu capital social (redes sociais) e capital cultural (e.g., formação acadêmica e certificações).

- Dotação social estratégica econômica: emprego (conhecimento de como empregar) de capital econômico próprio (e.g., dinheiro, propriedades, terra, máquinas e renda) e capital econômico controlado por outros agentes (e.g., empresa, pais).

- Dotação social estratégica volitiva: interesse, vontade, intenção e outras atitudes positivas em relação ao papel de gestor e envolvimento em práxis centrais estratégicas.

A categoria (vi) discurso da dotação social estratégica representa falas e textos que constituem uma ampla lógica de valorização e consenso em relação à necessidade de "se preparar para o mercado de trabalho". Os praticantes relataram a influência, em níveis variados durante sua trajetória, das arenas sociais designadas organização de trabalho, família, amigos, organizações de experiência e instituições de ensino, na reconstrução dessa 
lógica, na sedimentação da ideia de que "ser alguém na vida" depende de se preparar para o mercado, de que é preciso adquirir as habilidades necessárias ao trabalho gerencial, aquele realizado em níveis hierárquicos superiores das organizações. Os excertos abaixo exemplificam a presença desse discurso em intensidades contrastantes conforme a trajetória e arenas dos pesquisados.

[...] eu cuidava da rede do escritório do meu pai, isso me influenciou em querer ser dono do meu próprio nariz. Eu tava ali já. Já ele (i.e., se referindo ao outro sócio) já tem muita coisa pra cuidar da família. Desde cedo o pai dele tem essa preocupação. Isso aqui é mais um teste pra ele (Entrevistado 2, Administrador, sócio diretor, 24 anos). Meu pai, ele é bem empreendedor assim, ele sempre tá jogando em alguma coisa assim, acrescentar alguma coisa na loja dele, ele vive mirabolando, já tentou montar mercado, daí não deu certo, mas ele gosta, é empreendedorsão mesmo. Ele me dá uma força, mas eu achei cedo pra ter um negócio próprio (Entrevistado 11, Administrador, gerente financeiro, 22 anos). Minha mãe cuidava de casa e meu pai era piloto, mas eles não interferiram na minha formação, deixaram eu fazer o que quisesse, e eu escolhi Jornalismo. [...] Eu quero ser repórter policial (Entrevistada 10, estudante de Jornalismo, vendedora, 19 anos).

As (vii) constituições simbólicas dos praticantes da estratégia foram classificadas em uma formação tripartite: praticantes centrais, semiperiféricos e periféricos. Essa hierarquia ocorre em função do grau de atribuição de determinados significados a papéis, ou rótulos ocupacionais (e.g., diretor, coordenador, operário). Aos papéis de presidente e diretor, por exemplo, foram atribuídos fortemente os seguintes significados: diferenciação de habilidades em relação aos demais atores organizacionais, responsabilidade por resultados, formação específica em gestão, visão de mercado, capacidade de análise, distanciamento das operações, histórico de realizações, capacidade de fazer acontecer (mobilização de recursos e alcance de objetivos). Alguns desses significados associados a papéis de praticantes centrais são exemplificados nos excertos.

[...] o cara tem que ter um conhecimento grande, isso aí é algo que você não pode delegar. Isso é algo que é do presidente ou do proprietário (Entrevistado 5, Administrador, sócio diretor, 21 anos).

Ele tem que estar pensando lá na frente, sempre muito longe de onde a empresa tá [...] tirar as pessoas da zona de conforto, em relação à performance de negócio (Entrevistado 2, Administrador, sócio diretor, 24 anos).

Tem que conhecer tanto o ambiente externo quanto o ambiente interno muito bem, pra poder fazer a estratégia realmente ter um impacto e que seja viável (Entrevistado 6, estudante de Administração, vendedor, 19 anos).
Esses caras são bastante detalhistas, se ligam e podem prever o que vai acontecer com o mercado (Entrevistado 9, estudante de Publicidade e Propaganda, vendedor, 20 anos). 0 cara que tem o plano e faz o plano funcionar (Entrevistada 13, estudante de Comunicação Institucional, vendedora, 21 anos).

Por sua vez, os praticantes em posições semiperiféricas e, principalmente, periféricas são caracterizados simbolicamente pelo correspondente grau de distanciamento em relação a esses significados e também pelo maior envolvimento em práxis periféricas. Por fim, as relações entre as sete categorias identificadas na análise dos dados foram representadas graficamente na Figura 1.

$\mathrm{Na}$ articulação teórica entre os conceitos supracitados, foram selecionadas como categorias principais: práxis centrais e práxis periféricas. As práxis são consideradas recursos fundamentais na constituição simbólica do ator organizacional em diferentes domínios hierárquicos (vide Figura 1). No exame das proposições relacionais entre as categorias da pesquisa (Strauss \& Corbin, 2008), constatou-se forte influência do discurso da dotação social estratégica no envolvimento dos praticantes nas práxis centrais da estratégia. Esse discurso, o qual valoriza as posições de gestão nas organizações e atribui maior status e reputação aos atores sociais com maior nível hierárquico, faz das práxis centrais o alvo dos atores sociais durante sua trajetória.

Presente em variados graus nas diferentes arenas sociais, o discurso da dotação social estratégica faz com que atores sociais entendam a necessidade de valorizar e de se envolver mais intensamente em práxis centrais do que periféricas. Logo, aponta-se que tal discurso opera como um dos principais mecanismos de linguagem e de interação para institucionalização corrente das (i) normas de racionalidade e de progresso; e das (ii) forças sociopsicológicas e tecnoeconômicas na indústria do management. É exatamente o discurso, composto pela recorrência de falas e textos da dotação social estratégica, que contribui centralmente para difusão da expectativa de que atores organizacionais (força de trabalho no mercado) se comportem de modo racional, busquem ser eficientes. Do mesmo modo, as normas de progresso encontram também no discurso da dotação social estratégica o conteúdo de comunicação acerca do contínuo aperfeiçoamento da gestão. Em adição, o mesmo discurso sustenta as frustrações dos consumidores com as técnicas de gestão, as expectativas por novidade, a necessidade de diferenciação (forças sociopsicológicas) e a valorização do melhor desempenho (força tecnoeconômica). Portanto, subjacente às expectativas de normas de racionalidade e de progresso e às forças sociopsicológicas e tecnoeconômicas, está o discurso da dotação social estratégica recursivamente relacionado às práxis estratégicas. 
Figura 1. Construção social dos praticantes da estratégia

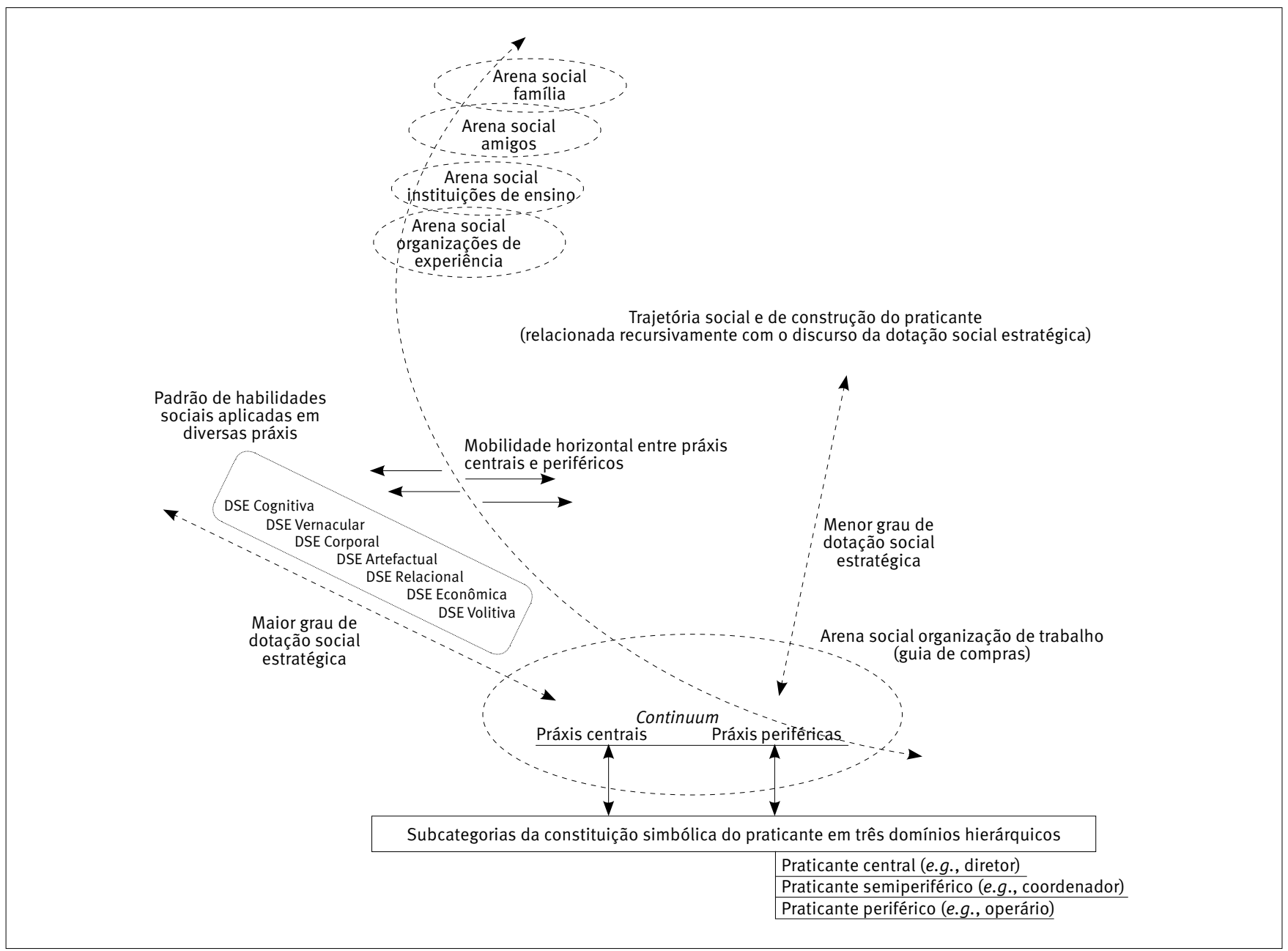

Por sua vez, a dotação social estratégica, não como discurso, mas como um padrão de uso, aquisição e aprimoramento de habilidades sociais - endowing - configura-se como habilitador do ator social para envolvimento em práxis mais centrais do que periféricas. A mobilidade horizontal para maior envolvimento em práxis centrais ao invés de periféricas depende de o praticante apresentar essas habilidades sociais legítimas para desempenho das práxis centrais. Habilidades sociais em ação ou, como designadas aqui, dotações sociais estratégicas (DSE); cognitiva, vernacular, corporal, artefactual, relacional, econômica e volitiva, oferecem maiores chances de envolvimento em práxis centrais. Isso não significa impossibilidade, mas dificuldade de mobilidade, pois, quanto mais envolvido em práxis periféricas, mais difícil desenvolver e principalmente aplicar e mostrar DSE. O menor grau de DSE (vide Figura 1) opera como uma restrição ao envolvimento em práxis mais centrais, não apenas por um critério técnico de potencial de sucesso desse ou daquele tipo de praticante em determinada posição, mas fundamentalmente em razão da legitimidade desse tipo de ator ao se considerarem os aspectos normativos do discurso da dotação social estratégica. Logo, duas considerações importantes devem ser detalhadas. A primeira é que a DSE, aplicação de habilidades sociais, se relaciona recursivamente com o discurso da DSE, pois uma é meio e produto da outra (Giddens, 1989). Na segunda consideração, interessa chamar atenção para o fato de que o conjunto de DSE, padrão de habilidades sociais em uso nas práxis centrais ao invés de periféricas, opera como elemento de segmentação de grupos de consumidores e produtores das técnicas, lógicas, ferramentas e conceitos da indústria do management.

Nesses termos, existem pelos menos dois segmentos de consumidores (Abrahamson, 1996; Benders \& Bijsterveld, 2000), considerados mais internamente homogêneos e discriminantes entre si, no que concerne aos produtos da indústria do management: (i) consumidores praticantes centrais da estratégia; e (ii) consumidores praticantes periféricos da estratégia. Enquanto o primeiro consome à sua maneira e de acordo com suas dota- 
ções estratégicas, o segundo grupo é consumidor e, ao mesmo tempo, mecanismo de apoio do processo de consumo dos praticantes centrais. Com frequência, os consumidores desse segundo grupo não têm conhecimento de todo o processo por detrás da aplicação de uma ferramenta gerencial, mas consomem, mais passivamente, em função de sua subordinação aos praticantes centrais, tal aplicação, e, desse modo, contribuem para a legitimação de tais ferramentas e da diferenciação hierárquica de papéis organizacionais.

A representação gráfica das categorias do estudo na Figura 1 destaca o continuum práxis centrais e periféricas também como plataforma para a constituição simbólica dos papéis dos praticantes da estratégia em diferentes domínios hierárquicos. Como já descrito, esse processo de constituição simbólica decorre de objetivações nominalistas dos praticantes, tais como: presidente, CEO, superintendente, diretor, gerente, coordenador, supervisor e operário, para citar apenas algumas. Esses rótulos foram agrupados hierarquicamente à luz dos conceitos de práxis centrais e periféricas, em: (i) praticantes centrais; (ii) praticantes semiperiféricos; e (iii) praticantes periféricos. Os dados da pesquisa revelaram que quanto mais um ator social está envolvido em práxis centrais da estratégia, mais são atribuídos a ele os significados: diferenciação de habilidades, responsabilidade por resultados, formação específica em gestão, visão de mercado, capacidade de análise, distanciamento das operações, histórico de realizações, capacidade de fazer acontecer. Essa tipificação (Berger \& Luckmann, 1998) reconstrói socialmente as noções ocupacionais já institucionalizadas e atribuídas a um e outro praticante da estratégia. Mas vale ressaltar as setas bidirecionais entre práxis centrais e a constituição simbólica dos praticantes da estratégia de um lado, e, de outro, as setas entre práxis periféricas e a constituição simbólica. Essas setas indicam que tanto um quanto outro tipo de práxis contribuem para a objetivação das subcategorias socialmente construídas que são ali categorizadas. Os atores sociais envolvidos em práticas periféricas atribuem os mesmos significados, antes apontados, aos papéis de presidente, diretor e outros papéis da gestão em função, não de seu envolvimento, mas do seu não envolvimento. Os significados de responsabilidade por resultados e diferenciação de habilidades, por exemplo, são nada ou fracamente associados às tipificações (Berger \& Luckmann, 1998) de praticantes periféricos. Esse modo de tipificação e a correspondente não identificação com ela fazem com que o praticante periférico tome como certo seu pertencimento a posições marginais à cúpula organizacional.

O processo de construção social dos praticantes da estratégia ocorre, portanto, em primeiro lugar, a partir de suas ações (práxis) (Berger \& Luckmann, 1998). Mais especificamente, a análise dos dados evidenciou que praticantes mais centrais da estratégia estão envolvidos mais intensamente em práxis centrais e, a partir das suas interações, constroem e reconstroem os significados que constituem simbolicamente noções hierarquizadas de papéis organizacionais. Do mesmo modo, tais significados atribuídos a esses papéis de praticantes condicionam os tipos de práxis nas quais eles se envolvem. Esse processo de construção social (constituição simbólica e objetivação dos papéis dos praticantes da estratégia) também é reforçado pelos atores sociais envolvidos nas práxis periféricas na medida em que tais atores, ou praticantes periféricos, não se envolvem mais intensamente nas práxis centrais, mas atribuem e extraem significados da sua não participação e da associação de determinadas atividades, práxis centrais, a determinados tipos de atores que atuam como praticantes centrais: presidente, diretor.

Mesmo evitando a apresentação de uma argumentação determinista, é preciso reconhecer que arenas sociais, em função do grau de compartilhamento do discurso da DSE, e o grau de DSE, padrão de habilidades sociais, dos atores sociais, condicionam, em alguma medida, as possibilidades de mobilidade do praticante periférico a uma posição de praticante central e condicionam mais fortemente o tipo de práxis em que o ator social se envolve nos estágios iniciais da vida profissional. Colocado mais amplamente, o que se passa ou não nas arenas sociais (e.g., grau de presença do discurso da dotação social estratégica) e a DSE figuram como fator de mais rápida e fácil habilitação do praticante ao exercício de atividades centrais da estratégia. As implicações para a indústria do management são muito diretas nesse ponto. É essencial que existam segmentos de consumidores com perfis diferentes para sustentação da indústria do management (Abrahamson, 1996; Benders \& Bijsterveld, 2000), por exemplo: (i) consumidores praticantes centrais da estratégia; e (ii) consumidores praticantes periféricos da estratégia. A legitimidade da indústria do management está ligada à legitimidade das suas ferramentas, conceitos e ideologias, e quem dá legitimidade ao uso feito pelos praticantes centrais da estratégia são esses próprios tipos de consumidores e também os praticantes periféricos. Portanto, a indústria do management figura como um sistema de produção de ferramentas, conceitos e ideologias gerenciais, como destacado por vários autores (e.g., Abrahamson, 1996; Abrahamson \& Eisenman, 2008; Abrahamson \& Fairchild, 1999) e caracteriza-se essencialmente como um espaço de construção social de seus consumidores e produtores que atuam como praticantes da estratégia. E, ao mesmo tempo que esse espaço possibilita a construção social de seus produtores e consumidores, ele também é construído e reconstruído discursivamente, por meio do discurso de DSE, no fértil solo da racionalidade instrumental que marca os valores mais caros da sociedade contemporânea (Kalberg, 1980; Weber, 2000). 


\section{CONCLUSÕES}

No presente estudo, buscou-se analisar como o processo de construção social dos praticantes da estratégia se relaciona com a indústria do management. A investigação foi levada a cabo por meio de um intenso período de observações, realizações de entrevistas e pesquisa de documentos em uma organização do setor de guias locais de compras pela internet. 0 exame da construção, ou, mais precisamente, da contínua reconstrução/transformação dos praticantes da estratégia, contemplou atores sociais em seus estágios iniciais de formação, o que facilitou a pesquisa em função da maior sensibilidade dos pesquisados à influência das modas e lógicas da indústria do management. Entretanto, essa facilidade acabou por impor alguns limites metodológicos. Para maior confiança acerca das relações teorizadas aqui, seria necessário que fossem analisados atores organizacionais em contextos negativos, ou seja, em contextos com características opostas às encontradas na organização pesquisada. A comparação poderia permitir testar mais precisamente as relações identificadas entre as categorias que emergiram dos dados.

A principal distinção deste trabalho em comparação aos já realizados sobre a indústria do management é a abordagem prática no tratamento da estratégia e de seu papel no funcionamento desse sistema de produção e consumo de técnicas, ferramentas e conceitos gerenciais. O olhar praxeológico dessa abordagem exigiu que se concebesse a estratégia como uma perspectiva, um modo de contemplar toda e qualquer atividade organizacional, central ou periférica. Assim, a estratégia, como objeto de análise, é definida como a própria organização. Mais especificamente, a natureza de open strategy, presente nessa abordagem, exige a não dicotomização entre planejamento e execução da estratégia, entre emergente e deliberado, ou entre formuladores e implementadores, pois tem como ponto de partida a consideração de qualquer elemento envolvido na estratégia enquanto ela ocorre. Quando se olha a organização acontecendo (Schatzki, 2006), está se observando sua estratégia.

Essa concepção menos restritiva na conceituação de estratégia permitiu dividir o que comumente se designa por práticas organizacionais em práxis centrais e práxis periféricas da estratégia. Essas práxis estão associadas respectivamente a atores da cúpula das organizações e a atores envolvidos nas atividades mais operacionais. A demarcação das fronteiras típicas entre o trabalho dos atores organizacionais dos diferentes domínios hierárquicos levou à conclusão de que esses tipos de práxis configuram o substrato da construção social, via constituição simbólica e reificação, das noções de praticantes da estratégia a partir das várias possibilidades de rotulação ocupacional (e.g., presidente, diretor, gerente, coordenador, operário). As rotula- ções foram enquadradas teoricamente, à luz dos conceitos de práxis centrais e periféricas da estratégia, nas subcategorias: (i) praticantes centrais; (ii) praticantes semiperiféricos; e (iii) praticantes periféricos. Portanto, práxis formam as noções de praticantes e essas noções de praticantes condicionam o grau de envolvimento de determinados atores sociais em práxis centrais ou periféricas. Esse processo de construção e reconstrução de tipificações toma ainda maior complexidade a partir da consideração da biografia dos atores sociais. Conforme a teorização apresentada aqui, os praticantes da estratégia são socializados no discurso da DSE durante sua trajetória, em maior ou menor grau, de acordo com a presença desse discurso e da constituição de suas arenas sociais. A internalização do discurso da dotação social contribui para o desenvolvimento de habilidades sociais relacionadas às práxis centrais da estratégia, que foram designadas DSE em ação.

Em resumo, tal processo mostra como os diferentes segmentos de consumidores, que são os praticantes da estratégia de diferentes domínios hierárquicos, exercem seus papéis, por meio da práxis, na contínua reconstrução social daquilo que Abrahamson (1996) chama de normas de racionalidade e de progresso e forças sociopsicológicas e tecnoeconômicas, e que dão sustentação à indústria do management. Sobretudo, vale notar que o maior envolvimento desses consumidores em práxis periféricas ou práxis centrais da estratégia emergiu aqui como um critério de segmentação dessa indústria. A literatura sobre a indústria do management assume que os consumidores das técnicas e conceitos gerenciais estão distribuídos num único grupo e com configuração homogênea. Entretanto, os achados do presente estudo apontam três segmentos de consumidores dessa indústria que atuam como praticantes da estratégia: praticantes centrais, semiperiféricos e periféricos. É importante destacar que as relações entre os distintos segmentos de consumidores do management constituem o que pode ser compreendido metaforicamente como uma espécie de sistema ecológico. A diversidade e a interdependência ecológica entre consumidores (praticantes da estratégia) da indústria do management ajudam a explicar a recorrente legitimação da estratificação que marca os limites dos seus distintos segmentos. Por meio da práxis, um tipo de praticante da estratégia legitima a autoridade e também o uso das ferramentas, técnicas e conceitos que estão sendo empregados pelo praticante de outro segmento. Em situações como essas, a diversidade de praticantes e a interdependência entre eles, que se materializa nas diversas práxis, revelam-se elementos cruciais à manutenção da estabilidade ecológica que sustenta a indústria do management no tempo e no espaço.

A principal contribuição deste trabalho é a tese de que, quando analisada sob uma perspectiva praxeológica e de onto- 
logia não hierárquica, conforme oferecida por Schatski (2001, 2005), a indústria do management é sustentada no tempo e no espaço, em primeiro lugar, pelas práxis sociais que dão corpo e movimento às organizações enquanto elas acontecem, bem como pelas relações de dominação e legitimação entre os diferentes estratos de praticantes ou consumidores dessa indústria. Tais práxis, no campo das práticas, figuram como unidades de confluência entre o discurso da DSE, os momentos de endowing ou de dotação estratégica dos praticantes, suas arenas, trajetórias sociais e constituições simbólicas de papéis nas organizações.

Por fim, a teorização proposta aqui oferece algumas possibilidades de estudos futuros. É preciso investigar como as diferentes práxis, desempenhadas por atores de distintos níveis hierárquicos, podem influenciar a inovação nas técnicas gerenciais com potencial para alcançar status de modas ou modismos gerenciais. Do mesmo modo, o exame dessas práxis pode revelar como os praticantes centrais e periféricos atuam na difusão das modas e modismos gerenciais. Outra oportunidade de pesquisa é a investigação do status dos diferentes praticantes e como essas divergências de status influenciam a busca pelo consumo de um ou outro tipo de inovação nos produtos da indústria do management.

\section{REFERÊNCIAS}

Abrahamson, E. (1991). Managerial fads and fashions: The diffusion and rejection of innovations. Academy of Management Review, 16(3), 586-612. doi:10.5465/AMR.1991.4279484

Abrahamson, E. (1996). Management fashion. Academy of Management Review, 21(1), 254-285.

Abrahamson, E., \& Eisenman, M. (2008). Employee-management techniques: Transient fads or trending fashions? Administrative Science Quarterly, 53(4), 719-744. doi:10.2189/asqu.53.4.719

Abrahamson, E., \& Fairchild, G. (1999). Management fashion: Lifecycles, triggers, and collective learning processes. Administrative Science Quarterly, 44(4), 708-740. doi:10.2307/2667053

Amernic, J. H., Losell, D. L., \& Craig, R. J. (2000). 'Economic value added' as ideology through a critical lens: Towards a pedagogy for management fashion. Accounting Education, 9(4), 343-367. doi:10.1080/09639280010033286

Barney, J. B. (1996). Gaining and sustaining competitive advantage. Massachusetts: Addison-Wesley Publishing Company.

Benders, J. (1999). Tricks and trucks: A case study of organization concepts at work. The International Journal of Human Resource Management, 10(4), 624-637. doi:10.1080/095851999340305

Benders, J., \& Bijsterveld, M. (2000). Leaning on lean: The reception of a management fashion in Germany. New Technology, Work and Employment, 15(1), 50-64. doi:10.1111/1468-005x.00064

Berger, P. L., \& Luckmann, T. (1998). A construção social da realidade. Petrópolis: Vozes.
Caldas, M. P., \& Wood, T. W., Jr. (2000). Fads and fashions in management: The case of ERP. RAE-Revista de Administração de Empresas, 40(3), 8-17. doi:10.1590_s0034-75902000000300002

Carson, P. P., Lanier, P. A., Carson, K. D., \& Guidry, B. N. (2000). Clearing a path through the management jungle: Some preliminary trailblazing. Academy of Management Journal, 43(6), 1143-1158.

Czarniawska, B., \& Panozzo, F. (2008). Preface: Trends and fashions in management studies. International Studies of Management \& Organization, 38(1), 3-12. doi:10.2753/imooo20-8825380100

Gibson, J. W., \& Tesone, D. V. (2001). Management fads: Emergence, evolution, and implications for managers. Academy of Management Executive, 15(4), 122-133.

Giddens, A. (1989). A constituição da sociedade. São Paulo: Martins Fontes.

Giroux, H. (2006). 'It was such a handy term': Management fashions and pragmatic ambiguity. Journal of Management Studies, 43(6), 1227-126o. doi:10.1111/j.1467-6486.2006.00623.x

Glesne, C. (1998). Becoming qualitative researchers. New York: Longman.

Jansson, J. (2011). Emerging (internet) industry and agglomeration: Internet entrepreneurs coping with uncertainty. Entrepreneurship \& Regional Development, 23(7-8), 499-521. doi:10.1080/08985620903505987

Kalberg, S. (1980). Max Weber's types of rationality: Cornerstones for the analysis of rationalization processes in History. American Journal of Sociology, 85(5), 1145-1179.

Lang, G., \& Ohana, M. (2012). Are management fashions dangerous for organizations? International Journal of Business and Management, 7(20), 81-89. doi:10.5539/ijbm.v7n2op81

Mamman, A. (2002). The adoption and modification of management ideas in organizations: Towards an analytical framework. Strategic Change, 11(7), 379-389. doi:10.1002/jsc.608

Maxwell, J. A. (2005). Qualitative research design. Thousand Oaks: Sage.

Mills, J., Bonner, A., \& Francis, K. (2006). The development of constructivist Grounded Theory. International Journal of Qualitative Methods, 5(1), 1-10.

Mintzberg, H., Ahlstrand, B., \& Lampel, J. (2010). Safári de estratégia. Porto Alegre: Bookman.

Mintzberg, H., Raisinghani, D., \& Théorêt, A. (1976). The structure of "unstructured" decision processes. Administrative Science Quarterly, 21(2), 246-275. doi:10.2307/2392045

Neuman, L. W. (1997). Social research methods: Qualitative and quantitative approaches. Boston: Allyn \& Bacon.

Nicolai, A. T., Schulz, A. C., \& Thomas, W. T. (2010). What Wall-Street wants: Exploring the role of security analysts in the evolution and spread of management concepts. Journal of Management Studies, 47(1), 162-189. doi:10.1111/j.1467-6486.2009.00862.x

Perkmann, M., \& Spicer, A. (2008). How are management fashions institutionalized? The role of institutional work. Human Relations, 61(6), 811-844. doi: 10.1177/0018726708092406

Porter, M. E. (1996). What is strategy? Harvard Business Review. Recuperado de https://hbr.org/

Reed, M. I. (1984). Management as a social practice. Journal of Management Studies, 21(3), 273-285. doi:10.1111/j.1467-6486.1984. tboo411.x 
Scarbrough, H., \& Swan, J. (2001). Explaining the diffusion of knowledge management: The role of fashion. British Journal of Management, 12(1), 3-12. doi:10.1111/1467-8551.00182

Schatzki, T. R. (2001). Introduction. In T. R. Schatzki, K. K. Cetina, \& E. Savigny, E. (Eds.), The practice turn in contemporary theory ( $\mathrm{pp}$ 1-14). London: Routledge.

Schatzki, T. R. (2005). Peripheral vision: The sites of organizations. Organization Studies, 26(3), 465-484. doi:10.1177/0170840605050876

Schatzki, T. R. (2006). On organizations as they happen. Organization Studies, 27(12), 1863-1873. doi:10.1177/0170840606071942

Seidman, I. (1998). Interviewing as qualitative research. New York: Teachers Press.

Shibutani, T. (1955). Reference groups as perspectives. American Journal of Sociology, 6o(6), 562-569.

Strauss, A., \& Corbin, J. (2008). Pesquisa qualitativa: Técnicas e procedimentos para o desenvolvimento de teoria fundamentada. Porto Alegre: Artmed.
Suchman, M. C. (1995). Managing legitimacy: Strategic and institutional approaches. Academy of Management Review, 20(3), 571-610.

Weber, M. (2000). Economia e sociedade (Vol. 1). Brasília: Editora UNB.

Whittington, R. (1996). Strategy as practice. Long Range Planning, 29(5), 731-735. doi:10.1016/0024-6301(96)00068-4

Whittington, R. (2006). Completing the practice turn in strategy research. Organization Studies, 27(5), 613-634. doi:10.1177/0170840606064101

Whittington, R., Cailluet, L., \& Yakis-Douglas, B. (2011). Opening strategy: Evolution of a precarious profession. British Journal of Management, 22(3), 531-544. doi:10.1111/j.1467-8551.2011.00762.x

Whittington, R., \& Melin, L. (2003). The challenge of organizing/strategizing. In A. M. Pettigrew, R. Whittington, L. Melin, C. Sanchez-Runde, F. A. J. van den Bosch, W. Ruigrok, \& T. Numagami (Eds.), Innovative forms of organizing (pp. 35-48). London: Sage Publications. 